\title{
Applying a utility based fuzzy probabilistic $\alpha$-cut method to optimize a constrained multi objective model
}

\author{
MOHAMMADREZA TORKJAZI and HAMED FAZLOLLAHTABAR
}

\begin{abstract}
.
This article is proposing an appropriate approach to solve a constrained multi objective model by using the theory of utility functions in fuzzy form. One of the approaches to optimize a multi objective mathematical model is to employ utility functions for the objectives. Recent studies on utility based multi objective optimization concentrate on considering just one utility function for each objective. But, in reality it is not reasonable to have a unique utility function corresponding to each objective function. Here, a constrained multi objective mathematical model is considered in which several utility functions are associated for each objective. All of these utility functions are uncertain and in fuzzy form, so a fuzzy probabilistic approach is incorporated to investigate the uncertainty of the utility functions for each objective and the total utility function of the problem will be a fuzzy nonlinear mathematical model. Since there are not any conventional approaches to solve such a model, a defuzzification method to change the total utility function to a crisp nonlinear model is employed. Meanwhile, $\alpha$-cut method is applied to defuzzify the conditional utility functions. This action results in changing the total utility function to a crisp single objective nonlinear model and will simplify the optimization process of the total utility function. The effectiveness of the proposed approach is shown by solving a test problem.
\end{abstract}

\section{REFERENCES}

[1] Arroyo, J. E. C. and Armentano, V. A., Genetic local search for multi-objective flowshop scheduling problems, European J. Oper. Res., 167 (2005), $717-738$

[2] Bernardo, J. J. and Lin, K.-S., An interactive procedure forbi-criteria production scheduling, Computers and Oper. Res., 21 (1994), 677-688

[3] Gupta, J. N. D., Palanimuthu, N. and Chen, C.-L., Designing a tabu search algorithm for the two-stage flow shop problem with secondary criterion, Production Planning and Control, 10 (1999), 251-265

[4] Gupta, J. N. D., Neppalli, V. R. and Werner, F., Minimizing total flow time in a two-machine flowshop problem with minimum makespan, Int. J. Production Economics, 69 (2006), 323-338

[5] Gupta, J. N. D., Hennig, K. and Werner, F., Local search heuristics for two-stage flow shop problems with secondary criterion, Computers and Oper. Res., 2 (2002), 123-149

[6] Jozefowiez, N., Semet, F. and Talbi, E., Multi-objective vehicle routing problems, European J. Oper. Res., 189 (2008), 293-309

[7] Keeney and Raiffa, Decisions with Multiple Objectives, Cambridge Uni. Press, (1993), 289-305

[8] Mirzapour Al-e-hashem, S. M. J., Malekly, H. and Aryanezhad, M. B., A multi-objective robust optimization model for multi-product multi-site aggregate production planning in a supply chain under uncertainty, Int. J. Production Economics, 134 (2011), 28-42

[9] Nagar, A., Heragu, S. and Haddock, J., A branch and bound approach for a 2-machine flowshop scheduling problem, J. Oper. Res. Society, 46 (1995b), $721-734$

[10] Rajendran, C., Heuristics for scheduling in flowshop with multiple objectives, European J. Oper. Res., 82 (1995), 540-555

[11] Rajendran, C., Two-stage flow shop scheduling problem with bi criteria, J. Oper. Res. Society, 43 (1992), 871-884

[12] Serifoglu, F. S. and Ulusoy, G., A bicriteria two-machine permutation flowshop problem, European J. Oper. Res., 107 (1998), 414-430

[13] T'kindt, V. and Billaut, J.-C., Multicriteria scheduling problems:A survey, RAIRO Oper. Res., 35 (2001), 143-163

[14] Yang, L., Jones, B. F. and Yang, S., A fuzzy multi-objective programming for optimization of fire station locations through genetic algorithms, European J. Oper. Res., 181 (2007), 903-915

[15] Yager, R. R., A representation of the probability of fuzzy subsets, FSS, 13 (1984), 273-283

[16] Zimmermann, H. J., Fuzzy Set Theory and Its Application, Kluwer Academic Publishers Group, (1996), 109-121

MAZANDARAN UNIVERSITY OF SCIENCE AND TECHNOLOGY

DEPARTMENT OF INDUSTRIAL ENGINEERING

BABOL, IRAN

E-mail address: hfazl@iust.ac.ir 